\title{
A ética das Relações Públicas. Um estudo comparativo dos códigos de conduta profissional em Espanha e Portugal e o código da Global Alliance for Public Relations and Communication Management
}

\author{
Public relations ethics. A comparative study of the \\ professional codes of conduct in Spain and Portugal \\ and the Global Alliance for Public Relations and \\ Communication Management code
}

\author{
Gisela Gonçalves; Isabel Ruiz-Mora
}

Cómo citar este artículo:

Gonçalves, Gisela; Ruiz-Mora, Isabel (2020). "A ética das Relações Públicas. Um estudo comparativo dos códigos de conduta profissional em Espanha e Portugal e o código da Global Alliance for Public Relations and Communication Management". El profesional de la información, v. 29, n. 3, e290316.

https://doi.org/10.3145/epi.2020.may.16

Artículo recibido el 11-11-2019

Aceptación definitiva: 22-04-2020

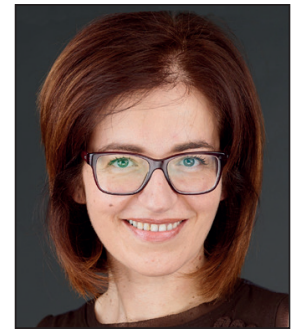

Gisela Gonçalves $\bowtie$ https://orcid.org/0000-0001-7001-3622

Universidade da Beira Interior Departamento de Comunicação e Artes Marquês de D’Ávila e Bolama, 6201-001, Covilhã, Portugal gisela.goncalves@labcom.ubi.pt

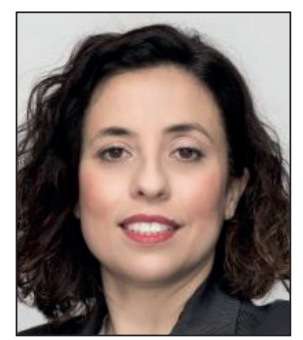

Isabel Ruiz-Mora https://orcid.org/0000-0003-0723-9850

Universidad de Málaga

Facultad de Ciencias de la Comunicación Dpto. de Com. Audiovisual y Publicidad

Campus de Teatinos, $\mathrm{s} / \mathrm{n}$.

29071, Málaga, España

isabelruiz@uma.es

\section{Resumo}

Os códigos deontológicos são uma reflexão moral centrada nos deveres e direitos de uma profissão, que estabelecem as normas morais mínimas exigíveis à sua atividade e que funcionam como um mecanismo auto-regulador da praxis profissional. Este artigo analisa os códigos de Relações Públicas das associações profissionais de Relações Públicas de Portugal e Espanha para perceber quais os valores comuns que guiam esta atividade. O objetivo da investigação foi duplo: 1) descrever comparativamente os códigos de Relações Públicas em vigor nas associações profissionais de dois países - Portugal e Espanha; 2) analisar comparativamente estes códigos à luz dos princípios globais da Global Alliance for Public Relations and Communication Management. Através de uma análise de conteúdo qualitativa comparativa, guiada pelos 16 princípios globais da Global Alliance, identificaram-se 7 valores fundamentais: (1) Trabalhar para o interesse público; (2) Honestidade, verdade e comunicação baseada em fatos; (3) Integridade; (4) Transparência; (5) Lidar com os públicos com justiça e respeito; (6) Comportar-se de forma a engrandecer a profissão; e (7) Atuar com profissionalismo. Apesar de existirem nuances no quadro normativo das associações profissionais locais, há princípios globais de prática que se destacam e que demonstram a possibilidade de um código de ética global para as Relações Públicas.

\section{Palavras-clave}

Relações Públicas; Ética das Relações Públicas; Associações profissionais; Códigos de ética; Portugal; Espanha; Global Alliance for Public Relations and Communication Management; Apecom; Apce; Dircom; Adecec. 


\begin{abstract}
Deontological codes are a moral reflection centered on the duties and rights of a profession, which set the minimum moral standards required for its activity and which function as a self-regulating mechanism of professional praxis. This article analyzes the Public Relations codes of ethics of the public relations professional associations of Portugal and Spain to understand the common values that guide this activity. The purpose of the research was twofold: 1) to describe comparatively the public relations codes of ethics in force in the professional associations of two countries - Portugal and Spain; 2) to analyze and compare these codes following the global principles of the Global Alliance for Public Relations and Communication Management. Through a qualitative comparative content analysis, guided by the Global Alliance's 16 global principles, 7 core values were identified: (1) Working for the public interest; (2) Honesty, truth and fact-based communication; (3) Integrity; (4) Transparency; (5) Deal with the public with fairness and respect; (6) Behave in such a way as to magnify the profession; and (7) Act with professionalism. Although there are nuances in the regulatory framework of the local professional associations, there are global principles of practice that stand out and demonstrate the possibility of a global code of ethics for public relations.
\end{abstract}

\title{
Keywords
}

Public Relations; Ethics; Professional associations; Codes of ethics; Portugal; Spain; Global Alliance for Public Relations and Communication Management; Apecom; Apce; Dircom; Adecec.

\section{Introdução}

Ao longo do tempo, os códigos de ética têm sido subscritos por associações profissionais um pouco por todo o mundo. Os códigos éticos são uma reflexão moral focada nos deveres e nos direitos de uma profissão que estabelecem as normas morais mínimas exigíveis a essa atividade. São, por isso mesmo, o primeiro passo para a auto-regulação da conduta profissional, um estágio fundamental no processo de profissionalização.

A prática das Relações Públicas e os códigos que guiam essa prática são influenciados pelo contexto local, pelo sistema cultural, económico, político e pela própria história do país, assim como pelo tipo de relacionamento que as organizações estabelecem com os públicos e o governo (Sriramesh; Verčič, 2009). Outra importante influência na construção de quadros normativos provém do contexto internacional, por mão das associações profissionais internacionais, nas quais muitas associações nacionais são filiadas e, também, pelas próprias empresas internacionais de Relações Públicas, que atuam em diferentes mercados locais. Assim, a profissionalização das Relações Públicas, enquanto parte de um processo social, económico e político em permanente mutação, refletirá necessariamente a tensão entre o global e o local.

A Global Aliance for Public Relations and Communication Management ${ }^{1}$-uma confederação das maiores associações de Relações Públicas e gestão da comunicação do mundo- parece estar consciente dessa tensão entre o local e o global. No dia 06 de fevereiro de 2018, anunciava a constituição de um grupo de trabalho que iria propor um novo Código de Ética Global para a profissão. De acordo com o comunicado, este novo Código Global iria salvaguardar as diferenças culturais ou idiomáticas dos vários países, assim como os códigos atualmente existentes.

O debate acerca da possibilidade de um código de ética universal não ocorreu apenas no campo profissional, no seio das associações. Este debate também teve início, há alguns anos atrás, no campo teórico. Kruckeberg (1993) e Roth et al. (1996) defenderam a possibilidade de um código universal de ética para a prática das Relações Públicas. Hunt e Tirpok (1993) forneceram uma estrutura para um código de ética universal e sugeriram mesmo uma estratégia e um calendário para a sua adoção. É comum encontrar estudos que exploram os códigos de ética das Relações Públicas no contexto nacional (Boynton, 2006; Pratt, 1994; Fitzpatrick, 2002; Shin; Cha, 2000; Gonçalves; Pereira; Toniolo, 2019), incluindo os casos português (Gonçalves, 2019) e espanhol (Fernández-Souto; Almansa-Martínez; Castillo-Esparcia, 2018). Menos comuns, são as pesquisas sobre esses códigos em perspetiva comparada (Ki; Kim, 2010; Wood, 2000; Taylor; Yang, 2014; Kolic-Stanic, 2019). Com este artigo, ambiciona-se colmatar esta lacuna através de um estudo comparativo entre os códigos portugueses e espanhóis e também, contribuir para o debate sobre a universalidade de um código de ética das Relações Públicas.

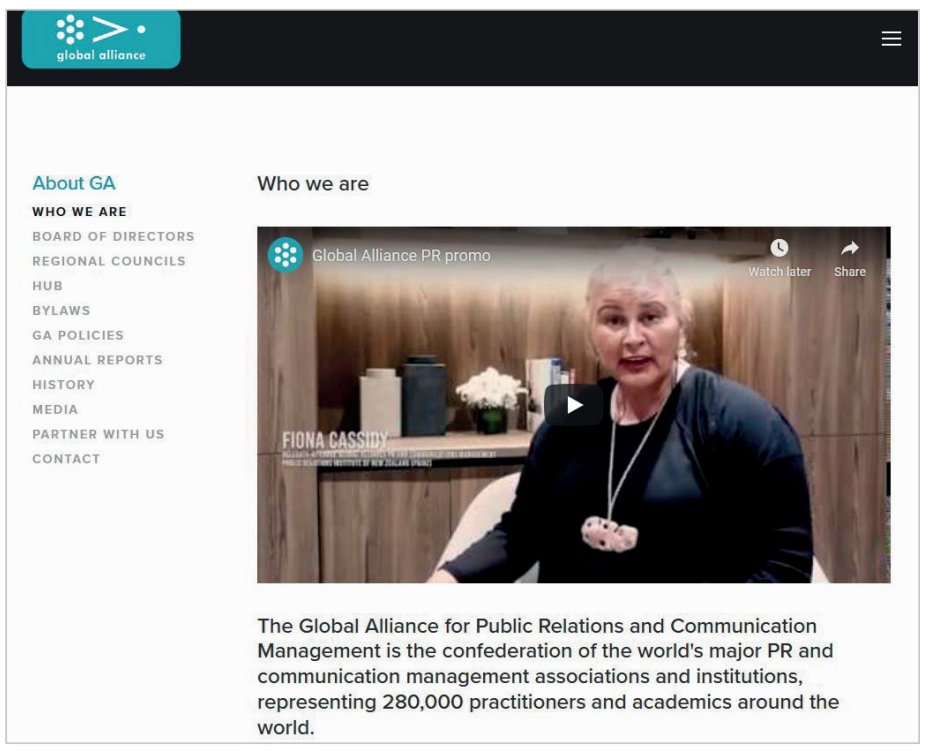

Site da Global Aliance for Public Relations and Communication Management. https://www.globalalliancepr.org 
Tendo por ponto de referência o "Global principles and code of ethics for professional public relations and communications practitioners" (Gobal Alliance Code, 2018), o objetivo principal deste artigo é perceber de que forma estes princípios globais se encontram refletidos nos códigos das associações profissionais nacionais. Assim, na primeira parte do texto debatemos o relevo da ética tanto no debate teórico como profissional sobre a práxis das Relações Públicas. Especial atenção é dada ao papel das associações profissionais enquanto guardiãs de uma prática ética, com o intuito de mapearmos os principais valores institucionalizados. Na segunda parte, estudamos os códigos éticos defendidos por associações nacionais, em particular, o caso das associações espanholas e portuguesas. Através de uma análise de conteúdo qualitativa dos 4 códigos em vigor nestes dois países, e tendo como referência os 16 princípios de conduta global defendidos pela Global Alliance, refletimos sobre as suas semelhanças e diferenças.

Em última análise, com esta investigação, ambicionamos perceber se um código de ética global, como o preconizado pela Global Alliance, tem correspondência nos códigos locais, como no caso de Portugal e Espanha, ou se existem diferenças nos quadros normativos dos respetivos contextos nacionais. Este estudo é relevante como ponto de partida para compreender, em investigações futuras, as diferenças e as semelhanças entre os códigos de países lusófonos (e.g. Brasil, Cabo Verde, Moçambique) e de língua espanhola (e.g. Argentina, Colombia, México).

\section{A ética na teoria e prática das Relações Públicas}

Quer no âmbito profissional quer acadêmico, a ética tem ocupado um lugar central no debate sobre o que são as Relações Públicas, o que fazem e como devem ser praticadas na contemporaneidade. Várias razões se poderiam apontar para esta indagação normativa, algumas históricas outras contextuais. As razões históricas prendem-se, essencialmente, com a origem difusa da profissão, muito próxima da propaganda, com a relação contenciosa com a esfera jornalística e, com a conotação com manipulação, ou spin, da informação e da opinião pública. As razões contextuais decorrem da atual "implosão da confiança" (Edelman, 2018) dos cidadãos nas instituições, governos e organizações, e nos próprios profissionais de Relações Públicas (Zerfass et al., 2019b), em um contexto mediático altamente fragilizado por fenómenos como as fake news.

De um ponto de vista académico, o tema da ética tem sido prolixo, fundamentando as principais teorias de Relações Públicas. É o caso do bem conhecido Excellence public relations project de James Grunig e sua equipa (Grunig, 1992). Centrado na defesa de uma teoria simétrica para a prática das Relações Públicas, é na sua essência uma teoria normativa das Relações Públicas:

"As Relações Públicas serão inerentemente éticas se seguirem os princípios do modelo simétrico bidireccional" (Grunig; Grunig, 1996, p. 40).

No âmago desta teoria está a defesa de uma praxis que almeja a compreensão mútua entre a organização e os públicos, implicando a modificação de comportamentos tanto por parte da organização como dos públicos. A compreensão mútua será alcançada através da prática de um diálogo onde os dois lados procuram chegar a um compromisso que proporcione soluções mutuamente benéficas para os problemas existentes (Grunig, 2001, p. 15).

Outra notória teoria do campo das Relações Públicas, intitulada Relationship Management, também coloca a ética no cerne da construção de relacionamentos (Broom; Casey; Ritchey, 1997; Ledingham; Bruning, 1998). Mas como

"uma relação mutuamente dependente não significa ser necessariamente mutuamente benéfica" (Ledingham; Bruning, 2001, p. 527),

a prática das Relações Públicas deverá ser fundamentada em valores comuns, partilhados pela organização e seus públicos. Da mesma forma, na Public Relations Dialogic Theory, Kent; Taylor (2002), inspirados em Pearson (1989) vêem a ética como o resultado de uma aproximação dialógica às interações das organizações com os públicos. No entanto, estão conscientes de que

“o diálogo não é uma panaceia. Uma abordagem dialógica não pode forçar uma organização a se comportar de forma ética, nem é apropriada em algumas circunstâncias" (Kent; Taylor, 2002, p. 24).

Bowen (2008) posiciona a função de Relações Públicas como a consciência das organizações e os profissionais como conselheiros éticos. Um posicionamento que só será possível se a prática das Relações Públicas se guiar por um imperativo ético universal de tipo kantiano (Bowen, 2004). Leeper (1996) propôs uma aplicação da Ética da discussão de Habermas à ética das Relações Públicas, realçando a consonância com o modelo bidirecional simétrico de Relações Públicas de Grunig. Outros autores, como Pearson (1989), Burkart (2004; 2009) ou Gonçalves (2013) também se inspiraram em Habermas para defender uma ética de tipo dialógico para a prática das Relações Públicas enquanto processo de intercompreensão. 


\subsection{Associações profissionais e códigos de conduta}

Do ponto de vista profissional, a ética tem sido debatida essencialmente no contexto das associações profissionais. Em todo o mundo, os códigos de ética das associações nacionais incorporam valores éticos que orientam a prática nos respetivos países (Greenwood; Suddaby; Hinings, 2002). Os códigos éticos refletem a evolução normativa de uma profissão e podem ser entendidos como o resultado de uma negociação contínua entre a profissão e a sociedade onde esses mesmos profissionais atuam (Frankel, 1989). As associações profissionais, na luta pelos interesses de classe, ocupam um papel fundamental na defesa das boas práticas profissionais, assim como na monitorização dessas mesmas práticas e na aplicação dos códigos éticos.

No caso das Relações Públicas, o primeiro código remonta a 1965, data em que a International Public Relations Association (IPRA) adoptou o código internacional de ética, conhecido como Código de Atenas. A autoria deste código pertence a Lucien Matrat, um pioneiro das Relações Públicas em França, que reflete uma visão optimista do mundo pós-2ª guerra mundial na sua forte ligação à Declaração de Direitos Humanos cunhada pelas Nações Unidas em 1948 (Watson, 2014). O código inicia-se com uma contextualização sobre os direitos fundamentais do homem declarando que os Relações Públicas, no exercício da sua profissão

"podem ajudar, conforme a maneira como a exerçam, a contribuir largamente para satisfazer essas necessidades intelectuais, morais e sociais dos homens";

considera que

"a utilização das técnicas que permitem entrar simultaneamente em contacto com milhões de pessoas, dá aos profissionais de Relações Públicas um poder que importa limitar pelo respeito da ética e dos valores da profissão"2.

Para Tim Traverse-Healy (1988), um dos fundadores do Chartered Institute of Public Relations (CIPR) e da International Public Relations Association (IPRA), o código de Matrat coloca em evidência os valores centrais das Relações Públicas: verdade, diálogo e respeito pelo interesse público. O estudo pioneiro desenvolvido por Lloyd (1973), sobre os códigos das associações profissionais de 26 países realçava que o Código de Atenas foi adotado, na íntegra ou com algumas variações, pela maioria dos membros das associações inquiridas (82\%). O Código de Atenas pode assim ser considerado o primeiro código global ou universal de Relações Públicas.

A falta de poder das associações para impor sanções aos infractores dos códigos é considerado um dos seus maiores problemas (Wright, 1993; Huang, 2001). Fitzpatrick (2002), por exemplo, traçou a evolução do código ético da associação americana de Relações Públicas, a Public Relations Society of America, ao longo de 50 anos, e verificou como a imposição do código tem sido fraca ao longo da história. A dificuldade em aplicar punições pode ser razão suficiente para olhar para os códigos como uma mera estratégia de gestão da imagem profissional, mas vários autores continuam a defender a sua importância. Kruckeberg (1989) sublinha que além de servirem de guias para a atividade profissional, os códigos permitem identificar o conjunto de expectativas subjacentes à profissão. Day (1991) defende que o código ético é a melhor forma de encorajar os profissionais a não confiarem em julgamentos meramente subjetivos interiorizando os valores subjacentes à profissão. Ao analisaram os códigos de 41 associações profissionais, Taylor; Yang (2014, p. 549) identificaram os três princípios-guias comuns:

- profissionalismo;

- defesa dos interesses do cliente;

- defesa da profissão e suas competências.

\subsection{Valores éticos institucionalizados}

Existem três principais associações internacionais de Relações Públicas:

- A Global Alliance for Public Relations and Communication Management é uma confederação das maiores associações de Relações Públicas e gestão da comunicação do mundo, representando 160,000 profissionais de todo o mundo.

- Fundada em 1970, a International Association of Business Communicators (IABC) apresenta-se como uma rede global de profissionais de comunicação distribuídos por mais de 70 países, comprometidos com a melhoria da eficácia organizacional por meio da comunicação estratégica ${ }^{3}$.

- A International Communications Consultancy Organisation (ICCO) é uma organização mundial que pretende ser a voz das consultoras de Relações Públicas em todo o mundo. Reúne associações nacionais que representam 55 países em todo o mundo: da Europa, África, Ásia, Oriente Médio, Américas e Australásia. Coletivamente, essas associações representam mais de 2.500 empresas de Relações Públicas ${ }^{4}$.

Em 2002, a Global Alliance dava início ao Global Alliance Ethical PR Project com o estudo comparativo dos principais códigos internacionais de Relações Públicas. Foram incluídos 16 códigos de diferentes países nessa comparação, mas não incluíam os casos de Portugal e Espanha ${ }^{5}$. Além do Código de Atenas, o estudo da Global Alliance colocou em evidência os códigos internacionais
A profissionalização das Relações

Públicas, enquanto parte de um processo social, económico e político em permanente mutação, refletirá necessariamente a tensão entre o global e o local 
mais reconhecidos e adoptados pelas associações profissionais: o Código de Lisboa, também conhecido como Código Europeu de Conduta Profissional; e o Code of Professional Standards for the Practice of PR. O primeiro foi fundado em França, em 1978, pela Confederation de Relations Publiques (CERP) e o último em 1950, pela Public Relations Society of America (PRSA).

Adoptado em 2003, o código da Global Alliance inicia-se com uma declaração de princípio:

"comprometemo-nos a nos comportar profissionalmente com integridade, verdade, precisão, justiça e responsabilidade para com os nossos clientes, para com os públicos dos nossos clientes e para uma sociedade informada" ${ }^{6}$.

A obrigação de os associados adoptarem um código de ética foi prática comum em outras associações internacionais, como é o caso da International Association of Business Communicators (IABC) com o Code of ethics for professional communicators e da International Communications Consultancy Organisation (ICCO) com o Stockholm charter?.

A leitura destes três códigos internacionais coloca em evidência os principais valores éticos e padrões de conduta institucionalizados pelas associações ao longo do tempo. Grunig salientou que os códigos de ética são valiosos porque realçam

"as lealdades divididas que os Relações Públicas experienciam quando tentam equilibrar os seus valores pessoais com os das organizações, públicos e profissionais" (Grunig, 2000, p. 29).

Estes valores e padrões de conduta agrupam-se habitualmente em volta dos conflitos ou dilemas de lealdade em relação ao: 1) dever para consigo mesmo (honestidade, verdade); 2) dever para com a organização cliente (integridade); 3) dever para com o empregador (lealdade, confidencialidade); 4) dever para com a profissão; e 5) dever para com a sociedade (transparência) (Seib; Fitzpatrick, 2006, p. 16).

No quadro 1 resumem-se esses valores e padrões de conduta recorrendo a excertos exemplificativos dos códigos analisados.

Quadro 1. Valores e normas de conduta presentes nos códigos das 3 principais associações internacionais de Relações Públicas (Global Alliance, IABC, ICCO)

\begin{tabular}{|c|c|}
\hline $\begin{array}{c}\text { Valores e } \\
\text { normas de conduta }\end{array}$ & Códigos da Global Alliance, IABC e ICCO \\
\hline Honestidade/verdade & $\begin{array}{l}\text { Ser honesto, não só com os outros, mas também consigo próprio; procurar a verdade e comunicar essa verda- } \\
\text { de, em primeiro lugar, a si mesmo (IABC). } \\
\text { Aderir aos mais elevados padrões de acuidade e verdade na prossecução dos interesses dos clientes e empre- } \\
\text { gadores }(G A) \text {. }\end{array}$ \\
\hline Integridade & $\begin{array}{l}\text { Conduzir os negócios com integridade e observar os princípios e espírito do código de forma a que a reputação } \\
\text { pessoal, a do empregador e da profissão de RP esteja protegida }(G A) \text {. } \\
\text { Não aceitar prendas nem pagamentos secretos por serviços profissionais de alguém que não seja cliente ou } \\
\text { empregador }(I A B C) \text {. }\end{array}$ \\
\hline Lealdade & $\begin{array}{l}\text { Ser fiel a quem se representa, ao mesmo tempo que se honra a obrigação de servir o interesse da sociedade e } \\
\text { se defende o direito à liberdade de expressão }(G A) \text {. } \\
\text { O trabalho para um novo cliente não deve começar sem que seja oferecido ao cliente mais antigo a oportuni- } \\
\text { dade de exercer quaisquer direitos inerentes aos seu contrato com a consultora (ICCO). }\end{array}$ \\
\hline Confidencialidade & $\begin{array}{l}\text { Proteger informação confidencial; Cumprir todos os requisitos legais na revelação de informação que possa } \\
\text { afectar o bem estar dos outros }(I A B C) \text {. } \\
\text { Não partilhar informação confidencial e que não seja publicamente conhecida sem o consentimento do cliente } \\
\text { (ICCO). }\end{array}$ \\
\hline Transparência & $\begin{array}{l}\text { Dar crédito a expressões que são pertença de outros e identificar as fontes e propósitos de toda a comunicação } \\
\text { disseminada para o público }(I A B C) \text {. } \\
\text { Não iludir conscientemente uma audiência em matéria de informação factual ou sobre os interesses que um } \\
\text { cliente representa }(I C C O) \text {. }\end{array}$ \\
\hline $\begin{array}{l}\text { Defesa da livre circulação de } \\
\text { informação }\end{array}$ & $\begin{array}{l}\text { Praticar uma comunicação honesta, verdadeira, e promover a livre circulação de informação essencial, de acor- } \\
\text { do com o interesse público; Corrigir imediatamente qualquer informação errada ou menos precisa pela qual se } \\
\text { seja responsável (IABC). } \\
\text { Funcionar no quadro de uma sociedade aberta onde a liberdade de expressão e uma imprensa livre criam o } \\
\text { contexto para a profissão de Relações Públicas }(I C C O) \text {. }\end{array}$ \\
\hline Enobrecimento da profissão & $\begin{array}{l}\text { Proporcionar ao cliente/empregador uma voz no fórum de ideias contribuindo para um debate público bem } \\
\text { informado }(G A) \text {. } \\
\text { Comprometer-se com uma comunicação verdadeira, exata e justa e que promova o respeito e compreensão } \\
\text { mútua }(I A B C) \text {. }\end{array}$ \\
\hline
\end{tabular}

No global, os três códigos defendem uma prática profissional com respeito pelos valores da honestidade, lealdade, integridade, transparência, defesa da livre circulação de informação, com consequências no enobrecimento de uma profissão cujo telos é estimular "a compreensão mútua" (IABC) e o "debate público bem informado" (Global Alliance). 
Neste sentido, os códigos destas 3 associações espelham o ideal normativo defendido por James Grunig no projeto da excelência das Relações Públicas:

"acreditamos que as Relações Públicas devem ser praticadas para servir o interesse público, para desenvolver a compreensão mútua entre as organizações e os seus públicos, e contribuir para um debate informado sobre os problemas sociais" (Grunig, 1992, p. 9).

\section{Metodologia}

A questão de investigação que guiou este estudo foi a seguinte: Os 16 princípios globais apresentados pela Global Alliance (2018) para a prática das Relações Públicas estão refletidos na identidade profissional defendida pelas associações profissionais nacionais? O objetivo da investigação foi duplo:

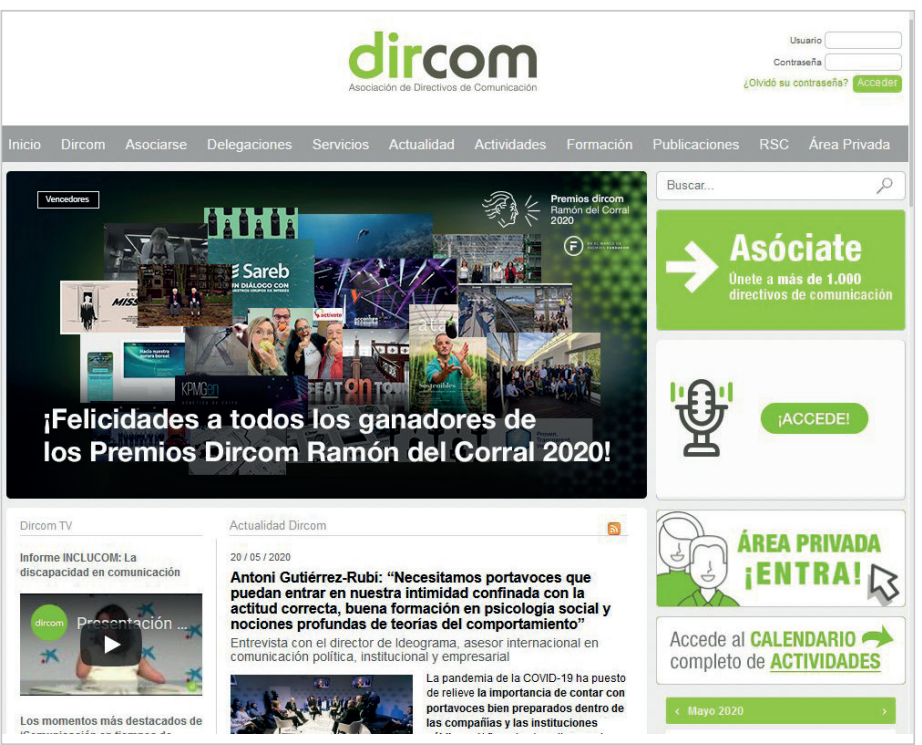

Site da Asociación de Directivos de Comunicación. http://www.dircom.org

- descrever comparativamente os códigos de Relações Públicas em vigor nas associações profissionais de dois países Portugal e Espanha;

- analisar comparativamente estes códigos à luz dos princípios globais da Global Alliance.

Para alcançar estes objetivos, recorreu-se a uma análise de conteúdo qualitativa dos códigos vigentes nas duas associações profissionais espanholas:

- Dircom (Asociación de Directivos de Comunicación);

- Adecec (Asociación de Empresas Consultoras en Relaciones Públicas y Comunicación);

e nas duas associações profissionais portuguesas:

- Apce (Associação Portuguesa de Comunicação de Empresa);

- Apecom (Associação Portuguesa das Empresas de Conselho em Comunicação e Relações Públicas).

No quadro 2 caracterizam-se os códigos das 4 associações profissionais alvo desta investigação.

Quadro 2. Códigos das 4 associações profissionais

\begin{tabular}{|c|c|c|c|c|}
\hline & \multicolumn{2}{|c|}{ Portugal } & \multicolumn{2}{|c|}{ Espanha } \\
\hline & Apce & Apecom & Dircom & Adecec \\
\hline Nome do código & $\begin{array}{l}\text { Código de Conduta do Gestor } \\
\text { de Comunicação Organiza- } \\
\text { cional e Relações Públicas }\end{array}$ & Código de Ética da Apecom & Código ético & Código ético \\
\hline Data de aprovação & 31 março 2019 & n. d. & Março 2002 & n. d. \\
\hline Autoria/Equipa & $\begin{array}{l}6 \text { membros ( } 5 \text { consultores + } \\
1 \text { professor universitário) }\end{array}$ & Direção Apecom & Direção Dircom & Direção Adecec \\
\hline Extensão do código & 988 palavras (8 artigos) & 660 palavras (18 artigos) & 320 palavras (11 artigos) & 585 palavras (17 artigos) \\
\hline Fontes do código & $\begin{array}{l}\text { United Nations Global } \\
\text { Compact. } \\
\text { Constituição da República } \\
\text { Portuguesa }\end{array}$ & Código de Estocolmo & Constituição da Espanha & $\begin{array}{l}\text { Constituição da Espanha. } \\
\text { Objetivos de Desenvolvimento } \\
\text { sustentável das Nações Unidas }\end{array}$ \\
\hline $\begin{array}{l}\text { Associado da Global } \\
\text { Alliance }\end{array}$ & $\operatorname{sim}$ & não & $\operatorname{sim}$ & não \\
\hline Acceso & http://www.apce.pt & $\begin{array}{l}\text { http://apecom.pt/a_ } \\
\text { apecom/codigo-de-etica }\end{array}$ & $\begin{array}{l}\text { http://www.dircom.org/ } \\
\text { sobre-dircom/codigo-etico }\end{array}$ & $\begin{array}{l}\text { http://adecec.com/wp-content/ } \\
\text { uploads/2019/07/C\%C3\%B3digo- } \\
\% \text { \%3\%89tico-ADECEC.pdf }\end{array}$ \\
\hline
\end{tabular}

As associações de Relações Públicas em Espanha e Portugal surgiram no mesmo período, na década de 80 e início da década de 90 . Fundada em 1982, Dircom é uma associação profissional que agrupa os diretores e os profissionais de comunicação de empresas, instituições e consultoras. Na atualidade, conta com mais de 1000 sócios e 8 delegações. De acordo com o seu site,

"a visão da Dircom é valorizar a função da comunicação e do diretor de comunicação nas organizações para que essa competência e os seus responsáveis sejam considerados uma área e direção estratégicos. A sua missão é realizada através de quatro eixos estratégicos: reconhecimento, desenvolvimento profissional, networking e gestão responsável / RSE".

http://www.dircom.org/sobre-dircom/que-es-dircom 
A Adecec foi fundada em 1991 por um grupo de profissionais representantes das principais empresas consultoras de Relações Públicas em Espanha, com o objetivo de difundir a prática de Consultoria de Comunicação e Relações Públicas neste país. Conta com 28 associados entre agências, empresas e instituições de ensino. De acordo com o seu site, têm como missão:

“impulsionar a práctica da profissão no nosso país, defendendo os interesses do sector e o reconhecimento de seu alto valor estratégico para as organizações". http://adecec.com/quienes-somos

Em Portugal, a Apecom foi constituída em 1989 e a Apce em 1990. Enquanto que a primeira representa as empresas consultoras de comunicação e Relações Públicas, a segunda engloba os profissionais de comunicação sediados em empresas, organizações e estudantes da área da comunicação institucional. Segundo os respetivos sites oficiais, a Apecom atualmente integra 24 empresas que são responsáveis por cerca de $70 \%$ do volume de negócios e do emprego do setor. A Apce regista sócios em nome individual (técnicos de comunicação), sócios jovens, 1 sócio honorário e ainda 90 empresas de destaque no panorama nacional ${ }^{8}$.

Em relação aos respetivos códigos éticos, no caso da Apecom, o seu site informa que subscrevem o Código de Estocolmo da ICCO, associação à qual estão associados, mas também que desenvolveram um código de ética para a profissão próprio ${ }^{9}$.

A Adecec, em Espanha, é um caso similar, além de subscreverem o Código da ICCO, tem também um código autónomo. Atualizado em 2009, o Código da Adecec baseia-se nos três princípios seguintes: "transparência, boas práticas e responsabilidade" 10 .

No caso da Apce, o seu Código de Conduta do Gestor de Comunicação Organizacional e Relações Públicas foi aprovado em assembleia geral de 31 de Março de 2009. O documento inicia-se com um preâmbulo sobre a missão principal do profissional:

"harmonizar e coordenar as práticas profissionais no âmbito da Comunicação organizacional e Relações Públicas e de perseguir a afirmação e credibilização da atividade do sector".

Antes de enunciar os principais valores e deveres profissionais há ainda espaço para definir a profissão de gestor de comunicação organizacional e Relações Públicas e as suas principais competências, a nível geral (eg. liderança e trabalho de equipa, pensamento estratégico, argumentação) e a nível específico (eg. pesquisa e monitorização; gestão e organização da informação; gestão de temas sensíveis).

A associação congénere da Apce em Espanha é a Dircom que apresenta o seu código de ética, aprovado em 2002, na seção Responsabilidade Social Corporativa (RSC). Os valores centrais realçados são: "rigor, transparência, confiança e veracidade". De acordo com o seu site, trabalha com a CEOE (Confederação Espanhola de Organizações Empresariais) para disseminar os seus princípios entre as associações empresariais ${ }^{11}$. Apenas a Apce (Portugal) e Dircom (Espanha) são associadas da Global Alliance.

Optou-se por comparar os dois países ibéricos por 2 razões principais:

- Ambos os países sofreram com grande intensidade a crise económica de 2008, que afetou o sector da comunicação. Procuramos perceber se os códigos refletem valores situacionais decorrentes dessa mesma crise;

- O mercado da comunicação ibérico é permeável a empresas e recursos humanos de ambos os países. Procuramos perceber se existem elementos contraditórios nos códigos, criando dilemas éticos à prática profissional dos dois lados da fronteira.

\section{Resultados e discussão}

A análise de conteúdo qualitativa e comparativa dos 4 códigos de Relações Públicas permitiu perceber de que forma os 16 princípios guias da Global Alliance for Public Relations and Communication Management, resumidos no quadro 1 , são contemplados nos ideais normativos da profissão em Portugal e em Espanha ${ }^{12}$. No global, a maioria dos princípios defendidos pela Gobal Alliance
A forma de os códigos de ética reforçarem a confiança pública numa profissão é feita através da declaração pública dos padrões éticos de comportamento que as pessoas podem esperar por parte de um grupo de profissionais 
estão também presentes nos códigos espanhóis e portugueses, ainda que com algumas nuances. Em 1이 lugar, da análise comparativa dos 4 códigos, sobressaem diferenças em relação à adesão aos princípios orientadores (9 princípios) e de prática profissional (7 princípios). No global, os princípios de prática profissional são mais consensuais do que os princípios orientadores junto das 4 associações estudadas (quadro 3).

Quadro 3. Conjunto de princípios e declarações para a prática ética das Relações Públicas proposto pela Global Alliance

\begin{tabular}{|c|c|c|c|c|c|}
\hline \multicolumn{2}{|r|}{ Princípios da Global Alliance } & Dircom & Adecec & Apce & Apecom \\
\hline \multirow{9}{*}{$\begin{array}{l}\text { Princípios } \\
\text { orientadores }\end{array}$} & Trabalhar para o interesse público & $\mathrm{x}$ & $\mathrm{x}$ & $\mathrm{x}$ & $x$ \\
\hline & Obediência às leis e respeito pela diversidade e pelos costumes locais & $x$ & $\mathrm{x}$ & $x$ & \\
\hline & Liberdade de expressão & $x$ & & $x$ & \\
\hline & Liberdade de reunião & & & $\mathrm{x}$ & \\
\hline & Liberdade de imprensa & $x$ & & $x$ & \\
\hline & Honestidade, verdade e comunicação baseada em fatos & $\mathrm{x}$ & $\mathrm{x}$ & $\mathrm{x}$ & $x$ \\
\hline & Integridade & $x$ & $\mathrm{x}$ & $x$ & $x$ \\
\hline & Transparência e divulgação & $x$ & $x$ & $x$ & $x$ \\
\hline & Privacidade & & $x$ & $x$ & $x$ \\
\hline \multirow{7}{*}{$\begin{array}{l}\text { Princípios da } \\
\text { prática }\end{array}$} & Comprometer-se com o aperfeiçoamento profissional contínuo & & $x$ & $x$ & \\
\hline & Evitar conflitos de interesse & $\mathrm{x}$ & $x$ & & $x$ \\
\hline & Advogar pela profissão & & $\mathrm{x}$ & $x$ & $x$ \\
\hline & Lidar com os públicos com justiça e respeito & $\mathrm{x}$ & $\mathrm{x}$ & $\mathrm{x}$ & $x$ \\
\hline & Não garantir resultados além da capacidade & $\mathrm{x}$ & & & $\mathrm{x}$ \\
\hline & Comportar-se de forma a engrandecer a profissão & $x$ & $x$ & $x$ & $x$ \\
\hline & Atuar com profissionalismo & $x$ & $x$ & $x$ & $x$ \\
\hline \multicolumn{2}{|l|}{ Total } & 12 & 12 & 14 & 11 \\
\hline
\end{tabular}

Fonte: Elaborado a partir dos principios da Global Alliance (2018).

Começando a análise pelos "princípios orientadores", os textos dos códigos evidenciam que apenas 4 em 9 princípios são subscritos por todas as associações: trabalhar para o interesse público; honestidade, verdade e comunicação baseada em factos; integridade e transparência. Tratam-se de princípios essencialmente centrados no valor da verdade, que como já se realçou antes, fundamenta a práxis de Relações Públicas desde a criação do Código de Atenas.

Os códigos portugueses são os mais claros na defesa do princípio "trabalhar para o interesse público":

"O Gestor de Comunicação Organizacional e Relações Públicas é leal à entidade que representa, salvaguardando sempre o interesse público" (Apce).

"Uma empresa membro deve conduzir as suas atividades profissionais tendo sempre em atenção o interesse publico" (Apecom).

Já os princípios da "integridade e transparência" são especialmente centrais e até redundantes nos códigos das associações espanholas:

"[o exercício da comunicação] deve ser feito com honestidade, integridade e transparência (Dircom)".

"Rejeitar a divulgação intencional de informações falsas ou deturpadas e garantir a manutenção completa e verdadeira das mesmas, comprovando a confiabilidade e a precisão de qualquer informação antes da sua divulgação (Adecec)".

"Garantir que os serviços prestados sejam calculados, entregues e contabilizados de maneira consistente com à ética e à transparência total" (Adecec).

Honestidade, verdade e comunicação baseada em factos é o princípio orientador mais claramente enunciado nos 4 códigos analisados, como se pode verificar nos excertos resumidos no quadro 4.

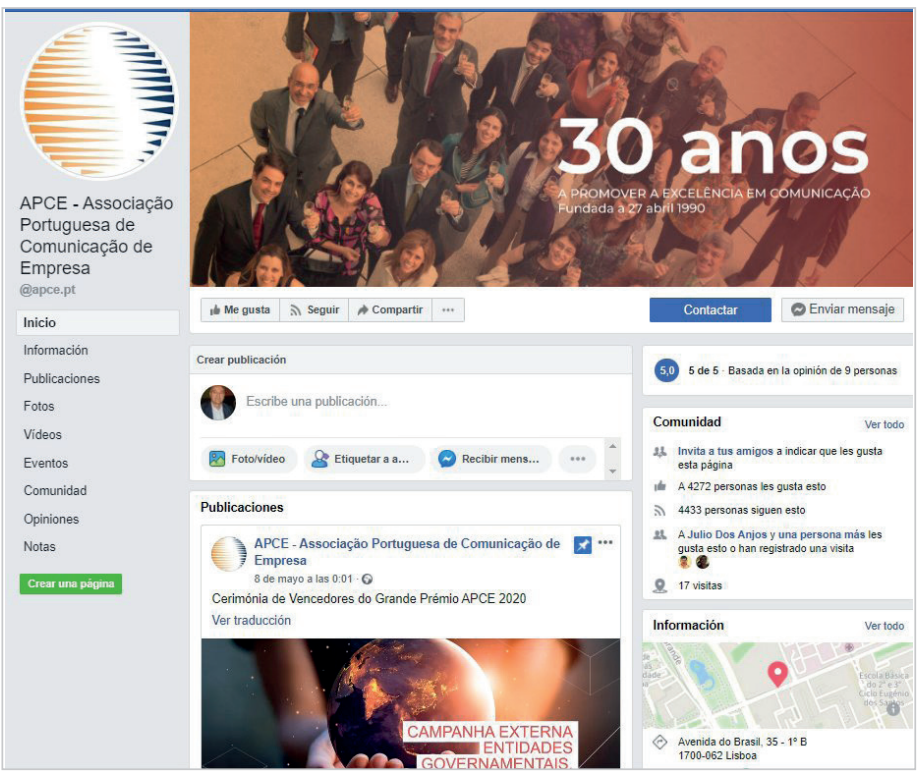

Página da Associação Portuguesa de Comunicação de Empresa no Facebook. https://www.facebook.com/apce.pt 
Quadro 4. Princípio orientador: Honestidade, verdade e comunicação baseada em factos

\begin{tabular}{|l|l|}
\hline \multicolumn{1}{|c|}{ Princípio } & \multicolumn{1}{c|}{ Códigos (excertos) } \\
\hline $\begin{array}{l}\text { Honestidade, verdade e } \\
\text { comunicação baseada em } \\
\text { factos }\end{array}$ & $\begin{array}{l}\text { O Gestor de Comunicação Organizacional e Relações Públicas adere ao exercício da atividade profissional apenas } \\
\text { com verdade, em defesa dos interesses da entidade com quem colabora, dos clientes desta, para com os colabora- } \\
\text { dores e os seus diversos públicos, não infringindo os princípios éticos por que se rege, salvaguardando o interesse } \\
\text { público (Apce). } \\
\text { Uma empresa membro deve respeitar a verdade, não propagando, intencional ou irrefletidamente, informações } \\
\text { falsas ou incorretas (Apecom). } \\
\text { [O exercício da comunicação] é um meio para gerar conhecimento, obter a confiança dos destinatários por meio } \\
\text { de informações verdadeiras e verificáveis, para que as organizações sejam responsáveis por suas ações e consis- } \\
\text { tentes com o alcance e o impacto que possam ter sobre a sociedade (Dircom). } \\
\text { Rejeitar a disseminação intencional de informações falsas ou deturpadas e velar pela manutenção completa e } \\
\text { verdadeira das mesmas, verificando a confiabilidade e a precisão de qualquer informação antes de sua divulgação } \\
\text { (Adecec). }\end{array}$ \\
\hline
\end{tabular}

Em relação aos princípios obediência às leis e respeito pela diversidade e pelos costumes locais e, privacidade, apenas uma das associações estudadas não o aponta no seu catálogo normativo. O 1 o princípio não está inscrito no código da Apecom e o 2 não surge no código da Dircom. Todas as outras associações são muito claras na defesa destes princípios, como se evidencia no quadro 5, acompanhando assim dois temas muito sensíveis -diversidade e privacidade- e que trespassam hoje o debate público nos mais variados níveis da sociedade.

Quadro 5. Princípios orientadores: Obediência às leis e respeito pela diversidade e aos costumes locais; Privacidade

\begin{tabular}{|c|c|}
\hline Princípios & Códigos (excertos) \\
\hline $\begin{array}{l}\text { Obediência às leis e res- } \\
\text { peito pela diversidade e } \\
\text { pelos costumes locais }\end{array}$ & $\begin{array}{l}\text { [O exercício da comunicação] deve respeitar a diversidade cultural, os valores sociais atuais e as diferentes crenças } \\
\text { religiosas. Baseia-se nos princípios da liberdade de expressão e informação e no direito de resposta (coberto pela } \\
\text { Constituição) (Adecec). } \\
\text { Respeitar as disposições gerais (leis, regulamentos, circulares de órgãos reguladores e de supervisão etc.) tanto do } \\
\text { país como dos setores em que o trabalho for realizado (Dircom). } \\
\text { Consciente do seu papel influenciador na sociedade, o Gestor de Comunicação Organizacional e Relações Públicas } \\
\text { fundamenta a sua atuação na aceitação de todos os princípios enunciados no Pacto Mundial das Nações Unidas e no } \\
\text { cumprimento da Constituição da República Portuguesa (Apce). }\end{array}$ \\
\hline Privacidade & $\begin{array}{l}\text { Manter a confidencialidade dos serviços prestados e as informações deles derivadas, tanto de clientes antigos como } \\
\text { do atuais, a menos que expressamente autorizado por eles, bem como proteger os direitos de privacidade dos clien- } \\
\text { tes, organizações e indivíduos (Adecec). } \\
\text { O Gestor de Comunicação Organizacional e Relações Públicas protege a informação confidencial relativa à entidade } \\
\text { para quem trabalha, bem como a que se refere a outras entidades e a pessoas a que a tanto esteja obrigado, não a } \\
\text { utilizando, em qualquer caso, para seu próprio benefício, ou de terceiros (Apce). } \\
\text { Uma empresa membro deve respeitar as confidências recebidas no decorrer da sua atividade profissional (Apecom). }\end{array}$ \\
\hline
\end{tabular}

Não deixa de ser curioso o facto de os valores da "liberdade de imprensa, liberdade de reunião e liberdade de expressão" serem os menos visíveis nos textos dos códigos analisados, apesar de serem essenciais à própria atividade das Relações Públicas. Apenas a Apce e o Dircom são claros na defesa destes princípios:

“O Gestor de Comunicação Organizacional e Relações Públicas acredita e defende o livre exercício dos direitos humanos, em especial, a liberdade de expressão, liberdade de reunião e liberdade dos meios de comunicação social, valores essenciais à prática da atividade profissional" (Apce).

[O exercício da comunicação] é baseado nos princípios da liberdade de expressão e informação e no direito de resposta (protegido pela Constituição) (Dircom).

Passando agora para a análise da presença dos 7 princípios de prática, como se pode verificar no quadro 3, apenas 3 princípios estão presentes em todos os 4 códigos analisados: "Lidar com os públicos com justiça e respeito; Comportar-se de forma a engrandecer a profissão; Atuar com profissionalismo". Já o princípio "Comprometer-se com o aperfeiçoamento profissional contínuo" está plasmado apenas nos código da Adecec e da Apce.

Os princípios "Evitar conflitos de interesse" e "Não garantir resultados além da sua competência" não se encontram claramente enunciados no código da Apce e da Adecec. Como se pode ler nos excertos dos códigos a seguir apresentados (quadro 6), o facto deste princípio remeter para dilemas mais comuns a consultores ou profissionais de agências de comunicação e não tanto a profissionais in-house poderia ser uma explicação plausível. No entanto, os estudos de Lieber (2005; 2008) sugerem que os profissionais de Relações Públicas de empresas (in-house) e de agências utilizam raciocínios bastante semelhantes nos seus quadros éticos e na tomada de decisões. 
Quadro 6. Princípios de prática: Evitar conflitos de interesse; Não garantir resultados além da sua competência

\begin{tabular}{|l|l|}
\hline \multicolumn{1}{|c|}{ Princípios } & \multicolumn{1}{c|}{ Códigos (excertos) } \\
\hline $\begin{array}{l}\text { Evitar conflitos de } \\
\text { interesse }\end{array}$ & $\begin{array}{l}\text { A agência deve informar o cliente por escrito sobre a posse de ações e interesses financeiros em empresas concorrentes } \\
\text { deste ou de fornecedores (Adecec). } \\
\text { Deve informar por escrito os clientes, os clientes potenciais e os empregadores sobre os conflitos de interesse que pos- } \\
\text { sam surgir (assim que se apresentem ou indicando as circunstâncias que possam levar a isso) com o objetivo de adotar } \\
\text { as medidas necessárias para os evitar (Adecec). } \\
\text { Uma empresa membro não deve aceitar a representação de interesses que possam estar em conflito ou em concorrên- } \\
\text { cia entre si (Apecom). }\end{array}$ \\
\hline $\begin{array}{l}\text { Não garantir resul- } \\
\text { tados além da sua } \\
\text { competência }\end{array}$ & $\begin{array}{l}\text { A comunicação] deve ser realizada com responsabilidade e eficiência, sem que o trabalho oferecido ou a mensagem } \\
\text { emitida possa criar expectativas ou garantir resultados inatingíveis para a organização ou, quando apropriado, para o } \\
\text { cliente (Dircom). } \\
\text { Uma empresa membro não deve garantir a obtenção de resultados que ela própria saiba de antemão não ter capaci- } \\
\text { dade de atingir (Apecom). }\end{array}$ \\
\hline
\end{tabular}

O princípio "Advogar pela profissão" não consta no código da Dircom, ao contrário da Apce, que sublinha claramente esse ideal:

"O Gestor de Comunicação Organizacional e Relações Públicas é responsável pela progressiva visibilidade e reputação da profissão, e, através da sua atitude, pelo reforço dos valores éticos e deontológicos" (Apce).

"O Gestor de Comunicação Organizacional e Relações Públicas é o principal agente de promoção e divulgação da sua actividade profissional, quer junto dos seus pares, quer das empresas e outras entidades potenciais utilizadoras destes serviços, quer, ainda, da sociedade em geral" (Apce).

No entanto, se olharmos para os códigos como um todo, podemos considerar que todas as 4 associações subscrevem esse princípio, sobretudo por subscreverem dois princípios muito similares -“Comportar-se de forma a engrandecer a profissão; e Atuar com profissionalismo", tal como exemplificado no quadro 7.

Quadro 7. Princípios de prática: Comportamentos que engrandecem a profissão; Conduta profissional

\begin{tabular}{|l|l|}
\hline \multicolumn{1}{|c|}{ Princípios } & \multicolumn{1}{c}{ Códigos (excertos) } \\
\hline \multirow{3}{*}{$\begin{array}{l}\text { Comportar-se de forma a } \\
\text { engrandecer a profissão }\end{array}$} & $\begin{array}{l}\text { Deve atuar de forma independente, respeitando a crítica responsável, oferecendo dados e argumentos convin- } \\
\text { centes, evitando a desqualificação, a falácia e o conflito de interesses, sempre de acordo com a legislação vigente. } \\
\text { (Dircom) } \\
\text { Evitar qualquer atividade que possa prejudicar o prestígio da Associação, ou de parte ou de todas as suas funções, } \\
\text { sendo essencial promover e aprimorar os princípios de boas práticas da consultoria de Relações Públicas e Co- } \\
\text { municação. (Adecec) } \\
\text { O Gestor de Comunicação Organizacional e Relações Públicas contribui para a credibilidade e constante dignifi- } \\
\text { cação da sua atividade, sendo elemento determinante na defesa de uma comunicação que respeite a verdade, a } \\
\text { lealdade, a confidencialidade e a liberdade, valores éticos intrínsecos aos princípios constantes dos documentos } \\
\text { a que se obriga. (Apce) } \\
\text { Uma empresa membro deve observar os mais elevados padrões de profissionalismo no exercício da função de } \\
\text { Comunicação e tratar com honestidade os seus clientes, antigos e atuais, colegas associados e outros profissio- } \\
\text { nais, intermediários, meios de comunicação, funcionários e, especialmente, o público. (Apecom) }\end{array}$ \\
\hline
\end{tabular}

Para concluir, a análise comparativa dos códigos vigentes em Portugal e Espanha, permite constatar que as associações nacionais seguem de forma muito próxima os 16 princípios globais propostos pela Global Alliance. Em média, as 2 associações de Espanha seguem 12 dos 16 princípios. Em Portugal, a Apce adota 14 princípios e, em número inferior, a Apecom 11. Contudo, apenas 7 princípios são seguidos por todas as associações estudadas:

- trabalhar para o interesse público;

- honestidade, verdade e comunicação baseada em fatos;

- integridade;

- transparência;

- lidar com os públicos com justiça e respeito;

- comportar-se de forma a engrandecer a profissão;

- atuar com profissionalismo.

O princípio menos plasmado nos códigos é "Liberdade de reunião", identificado apenas no código da Apce. Além deste princípio, os princípios menos adotados, porque presentes nos códigos de apenas duas associações, uma portuguesa (Apce) e outra espanhola (Dircom) são: "liberdade de expressão" e "liberdade de imprensa". As associações mais idênticas ao nível dos princípios adotados são a Apce e a Adecec.

Entre os 4 códigos, a Apce posiciona-se como o código mais próximo dos 16 princípios da Global Alliance. Simultaneamente, este é também o código que melhor se distingue, em conjunto com o código da Adecec, não só do quadro normativo da Global Alliance mas dos outros códigos antes analisados, pelo destaque concedido ao dever para com a 
responsabilidade social e ambiental:

"O Gestor de Comunicação Organizacional e Relações Públicas é elemento ativo na sensibilização da consciência social, na defesa do planeta, do meio ambiente, da biodiversidade, na luta contra a fome, a guerra, todas as formas de violência e injustiça, defendendo e apoiando políticas socialmente sustentáveis, a favor da paz" (Apce).

"Evitar campanhas ou acções para um cliente que incitem a comportamentos ilegais ou antiéticos e alinhar, na medida do possível, com valores positivos no âmbito da ODS (Objetivos de Desenvolvimento Sustentável das Nações Unidas)" (Adecec).

Um outro aspeto diferenciador pode ser identificado nos códigos da Adecec e da Apce. O código da Adecec faz alusão expressa à importância de tratar bem os empregados e os colegas, além de todos os outros coletivos, de forma justa, honesta e transparente:

"Tratar os colaboradores, colegas, clientes, fornecedores, meios de comunicação social, entidades públicas e público em geral de forma justa, honesta e transparente, respeitando o interesse da sociedade na realização das actividades" (Adecec).

A Apce também sublinha a importância de

"aderir ao exercício da atividade profissional apenas com verdade, em defesa dos interesses da entidade com quem colabora, dos clientes desta, para com os colaboradores e os seus diversos públicos" (Apce).

Finalmente, uma nota relativa à questão da imposição dos códigos. Os códigos analisados apelam essencialmente à auto-regulação, através da denúncia dos infratores aos códigos, mas nenhum refere explicitamente quais as consequências ou sanções disciplinares a aplicar.

Consideramos pertinente incluir ainda uma breve contextualização sobre a realidade profissional em Espanha e Portugal para que se possa entender o alcance, o significado e o valor dos resultados alcançados. Mais concretamente, discutimos os nossos resultados à luz do estudo mais recente da European Communication Monitor (ECM) 2019, Exploring trust in the profession, transparency, artificial intelligence and new content strategies. Results of a survey in 46 countries (Zerfass et al., 2019a). Focamos a atenção nos dados sobre a confiança na profissão, pois está intimamente relacionada com o nosso trabalho. A confiança decorre de uma prática profissional regida pelos valores e princípios habitualmente promovidos pelas associações e plasmados nos seus códigos éticos.

Na Europa, a confiança na profissão de Relações Públicas varia de acordo com o tipo de stakeholder consultado (Zerfass et al., 2019a). Os gestores confiam $67,5 \%$, os influenciadores/ bloggers $47,5 \%$, os jornalistas $39,1 \%$ e a população em geral $27,6 \%$. Em termos gerais, os níveis de confiança na profissão são mais positivos nos países do norte e oeste da Europa do que nos do sul e leste. No caso específico de Espanha e Portugal, encontramos dados semelhantes, embora com algumas diferenças sutis (quadro 8). Na Espanha, são os gestores e os jornalistas que mais confiam na profissão, enquanto que em Portugal já são os gestores e os influenciadores/bloggers.

Quadro 8. Confiança na profissão em Espanha e Portugal

\begin{tabular}{|c|c|c|c|c|}
\hline Stakeholders & Gestores & Influenciadores / bloggers & Jornalistas & População em geral \\
\hline Espanha & $65,1 \%$ & $49,6 \%$ & $53,1 \%$ & $30,6 \%$ \\
\hline Portugal & $60,5 \%$ & $65,3 \%$ & $37,5 \%$ & $36,8 \%$ \\
\hline
\end{tabular}

Fonte: Zerfass et al. (2019, p. 20).

Se olharmos para os resultados do ECM 2019 sobre a confiança depositada nos departamentos de comunicação e nas agências, descobrimos que na Europa, 85,1 \% dos gestores (da própria organização) e os clientes têm uma atitude positiva (confiança) em relação aos departamentos de comunicação / agências; seguido por 73,9\% dos jornalistas (com quem interagem), 70,1\% da população geral (que utiliza os seus media, canais e eventos) e 68,4\% dos influenciadores / bloggers (com quem interagem). No caso específico de Espanha e Portugal, encontramos dados muito semelhantes (quadro 9), com variações na confiança dos jornalistas, que é maior na Espanha, e nos influenciadores / bloggers, em Portugal.

Quadro 9. Confiança nos departamentos e agências de comunicação

\begin{tabular}{|l|c|c|c|}
\hline \multicolumn{1}{|c|}{ Stakeholders } & $\begin{array}{c}\text { Gestores (da própria or- } \\
\text { ganização) e os clientes }\end{array}$ & $\begin{array}{c}\text { Jornalistas (com quem } \\
\text { interagem) }\end{array}$ & $\begin{array}{c}\text { População em geral (que } \\
\text { utiliza os seus media, } \\
\text { canais e eventos) }\end{array}$ \\
\hline Espanha & $84,7 \%$ & $79,7 \%$ & $68,2 \%$ \\
\hline Portugal & $83,5 \%$ & $69,7 \%$ & $67,5 \%$ \\
\hline
\end{tabular}

Fonte: Zerfass et al. (2019, p. 24). 


\section{Conclusões}

Seja em Relações Públicas ou em qualquer outra profissão, os códigos de ética existem por pelo menos duas razões interrelacionadas: reforçar a confiança do público na profissão e orientar a conduta profissional. A forma de os códigos de ética reforçarem a confiança pública numa profissão é feita através da declaração pública dos padrões éticos de comportamento que as pessoas podem esperar por parte de um grupo de profissionais. Nessa aceção, um código de conduta atua como uma espécie de promessa feita por um grupo de profissionais àqueles que confiam nos seus serviços.

Os 16 princípios listados pela Global Alliance for Public Relations and Communication Management prometem um padrão ideal de comportamento, que reflete as questões éticas mais comuns à profissão e que são guias no processo de tomada de decisões e de ação. São apresentados como um modelo normativo universal para a prática das RP, comum a qualquer país.

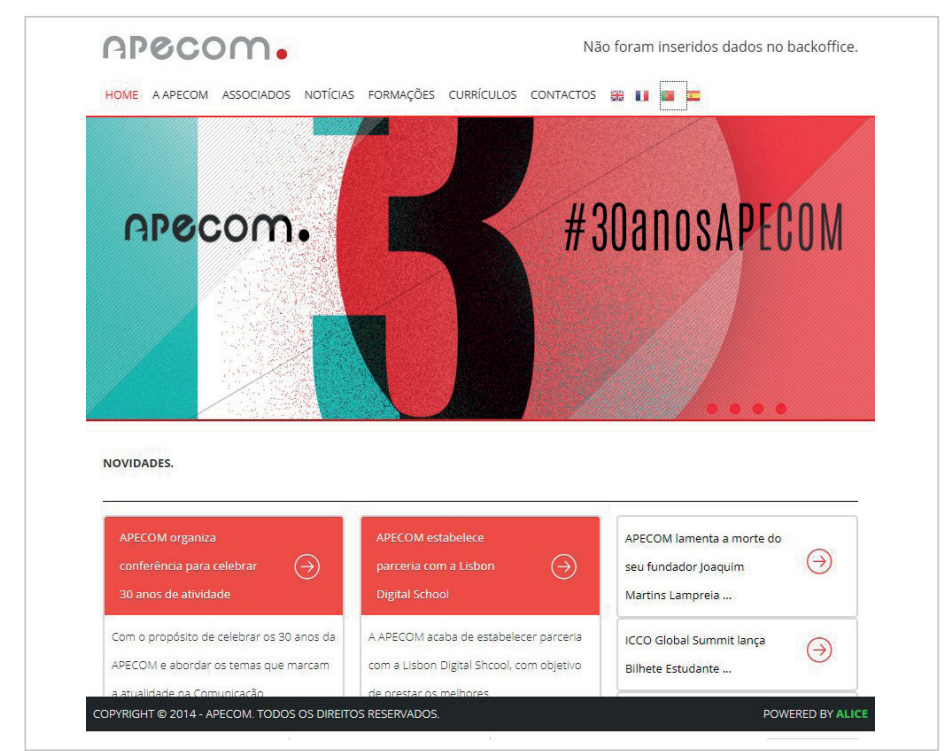

Site da Associação Portuguesa das Empresas de Conselho em Comunicação e Relações Públicas.

https://apecom.pt

Com a nossa pesquisa pudemos confirmar que apenas 7 dos 16 princípios globais da Global Alliance se encontram refletidos simultaneamente nos códigos de ética do Dircom e Adecec, em Espanha, e da Apce e Apecom, em Portugal:

- Trabalhar para o interesse público.

- Honestidade, verdade e comunicação baseada em fatos.

- Integridade.

- Transparência.

- Lidar com os públicos com justiça e respeito.

- Comportar-se de forma a engrandecer a profissão.

- Atuar com profissionalismo.

No entanto, quando analisados individualmente, também verificámos que os quatro códigos seguem de forma muito próxima os 16 princípios globais propostos pela Global Alliance. Em média, as 2 associações de Espanha (Dircom e Adecec) seguem 12 dos 16 princípios. Em Portugal, a Apce adota 14 e a Apecom 11 princípios.

A análise permitiu perceber que a sustentabilidade é apresentada como um dos desafios para os profissionais e agências de Relações Públicas, em Portugal e em Espanha, mas não é evidente no quadro normativo da Global Alliance. Na verdade, não é de surpreender que a responsabilidade social e o cumprimento dos Objetivos de Desenvolvimento Sustentável das Nações Unidas sejam inscritos em quadros normativos. Não podemos ignorar essa relação, a gestão das relações com o público está no coração da RSE como uma das funções das Relações Públicas e os profissionais devem assumi-la como compromisso com a sociedade. O papel da ética na comunicação da RSE é indiscutível e portanto, é compreensível que as associações profissionais o promovam, contribuindo para a credibilidade e confiança junto dos diferentes stakeholders.

Da mesma forma, os códigos analisados também colocam em evidência como as relações com os funcionários surgem como um desafio para as agências. A gestão de relações internas pressupõe o reconhecimento da importância de uma boa comunicação interna, centrada no relacionamento entre os membros da organização com o objetivo de desenvolver um clima de confiança e promover a eficiência do trabalho. É inevitável pensar na forma como a crise económica afectou o sector da comunicação em geral e, consequentemente, os seus empregados.

Este estudo abre caminhos para investigações futuras. A análise comparativa foi circunscrita apenas a dois países europeus e ibéricos. Seria importante alargar a pesquisa a outros países de fala portuguesa e espanhola localizados em outros continentes, pois será mais provável a existência de diferenças económicas, sociais e culturais com consequências nos quadros normativos da prática das Relações Públicas. Com este estudo tampouco se investigou a forma como os profissionais de Relações Públicas percecionam e utilizam os códigos éticos para
A análise permitiu perceber que a sustentabilidade é apresentada como um dos desafios para os profissionais e agências de Relações Públicas. Não é de surpreender que apareça a responsabilidade social e o cumprimento dos Objetivos de Desenvolvimento Sustentável das Nações Unidas 
guiar a sua prática quotidiana. A inclusão de entrevistas aos responsáveis das associações e aos próprios profissionais sobre a sua perceção em relação às questões éticas mais prementes à profissão, seria também outra possível linha futura de investigação. Apesar de já existirem estudos sobre essa relação a nível internacional, novas pesquisas poderão analisar a forma como os códigos auxiliam os processos de decisão de comportamento de uma forma global ou se variam consoante o contexto social, económico ou mesmo político, a nível nacional.
Identificaram-se 7 valores fundamentais: Trabalhar para o interesse público; Honestidade, verdade e comunicação baseada em fatos; Integridade; Transparência; Lidar com os públicos com justiça e respeito; Comportar-se de forma a engrandecer a profissão; e Atuar com profissionalismo

\section{Notas}

1. A Global Alliance for Public Relations and Communication Management representa cerca de 160,000 profissionais de todo o mundo. De acordo com o seu site, tem a missão de unir a profissão de Relações Públicas e aumentar os padrões profissionais a nível global, partilhar conhecimento em benefício dos seus membros e ser uma voz global em prol dos interesses públicos das Relações Públicas:

http://www.globalalliancepr.org

2. O Código de Atenas pode ser consultado na íntegra em:

https://www.ipra.org/static/media/uploads/pdfs/ipra_code_of_athens.pdf

3. Informações disponíveis no site oficial

https://www.iabc.com

4. Dados disponíveis em https://www.iccopr.com

5. Fonte:

https://static1.squarespace.com/static/561d0274e4b0601b7c814ca9/t/56c20345c2ea510748cb2768/1455555401036/ ethics-Benchmarking.pdf

6. O código de ética da Global Alliance pode ser consultado na íntegra aqui: https://static1.squarespace.com/static/561d0274e4b0601b7c814ca9/t/56c201e11d07c00b66443b47/1455555043172/ GA+Code+of+Ethics.pdf

7. O código da $I A B C$ pode ser consultado na íntegra aqui: https://www.iabc.com/wp-content/uploads/2016/02/08-Code-of-Ethics_IEB-Approved_4-May-2016.pdf

O Código de Estocolmo pode ser acedido aqui: https://iccopr.com/wp-content/uploads/2015/01/StockholmCharter.pdf

8. Os sites institucionais da Apce, Apecom, Dircom e Adecec poden ser consultados, respectivamente, em: http://www.apce.pt (em maio de 2020, este site da Apce não está operacional)

http://www.apecom.pt

http://www.dircom.org

http://www.adecec.com

9. O código de ética da Apecom está disponível aqui: http://apecom.pt/a_apecom/codigo-de-etica

10. O código de ética da Dircom está disponível aqui: http://www.dircom.org/sobre-dircom/codigo-etico

11. O código de ética da Adecec está disponível aqui: http://adecec.com/adecec-aprueba-el-nuevo-codigo-etico-de-las-consultoras-de-comunicacion-en-su-asamblea-general-2019

12. Os 16 princípios estão disponíveis aqui: https://www.globalalliancepr.org/code-of-ethic

Ao longo do artigo utiliza-se a versão em português (traduzido pelas autoras).

\section{Referências}

Bowen, Shannon A. (2004). "Expansion of ethics as the tenth generic principle of public relations excellence: A Kantian theory and model for managing ethical issues". Journal of public relations research, v. 16, n. 1, pp. 65-92. https://doi.org/10.1207/s1532754xjprr1601_3 
Bowen, Shannon A. (2008). "A state of neglect: Public relations as 'corporate conscience' or ethics counsel". Journal of public relations research, v. 20, n. 3, pp. 271-296.

https://doi.org/10.1080/10627260801962749

Boynton, Lois A. (2006). "What we value: A Delphi study to identify key values that guide ethical decision-making in public relations". Public relations review, v. 32, n. 4, pp. 325-330.

https://doi.org/10.1016/j.pubrev.2006.09.001

Broom, Glen M.; Casey, Shawna; Ritchey, James (1997). "Toward a concept and theory of organization-public relationships". Journal of public relations research, v. 9, n. 2, pp. 83-98.

https://doi.org/10.1207/s1532754xjprr0902_01

Burkart, Roland (2004). "Consensus-oriented public relations (COPR): a concept for planning and evaluation of public relations”. In: Van-Ruler, Betteke; Verčič, Dejan (eds.). Public relations and communication management in Europe. Berlin: Mouton de Gruyer, pp. 459-466. ISBN: 3110176114

https://doi.org/10.1515/9783110197198

Burkart, Roland (2009). “On Habermas: understanding and public relations”. In: Ihlen, Øyvind; Van-Ruler, Betteke; Fredriksson, Magnus (eds.). Public relations and social theory. Key figures and concepts. New York and London: Routledge, pp. 141-165. ISBN: 9781138281295

Day, Louis A. (1991). Ethics in mass communications: cases and controversies. Belmont, CA: Wadsworth. ISBN: 9780 534637149

Edelman (2018). Trust barometer.

https://www.edelman.com/sites/g/files/aatuss191/files/2018-10/2018_Edelman_Trust_Barometer_Global_Report_FEB.pdf

Fernández-Souto, Ana-Belén; Almansa-Martínez, Ana; Castillo-Esparcia, Antonio (2018). “Ética en las relaciones entre los medios de comunicación y los gabinetes de comunicación”. Prisma social: revista de investigación social, n. 22, pp. 1-19.

https://revistaprismasocial.es/article/view/2531

Fitzpatrick, Kathy R. (2002). "Evolving standards in public relations: A historical examination of PRSA's codes of ethics". Journal of mass media ethics, v. 17, n. 2, pp. 89-110.

https://doi.org/10.1207/S15327728JMME1702_02

Frankel, Mark S. (1989). "Professional codes: Why, how, and with what impact?". Journal of business ethics, v. 8, n. 2-3, pp. 109-115.

https://doi.org/10.1007/BF00382575

Gonçalves, Gisela (2013). A ética das Relações Públicas. Coimbra: Minerva Coimbra. ISBN: 9789727983346

Gonçalves, Gisela (2019). "A ética profissional das Relações Públicas: uma análise comparativa dos códigos de conduta a partir do caso português". In: Sebastião, Sónia; Martins, Paulo (org.). Ética em comunicação. Reflexão sobre os atributos, os desafios e as práticas. Lisboa: ISCSP, Universidade de Lisboa, pp. 47-62. ISBN: 9789896461348 https://bit.ly/3cz22RG

Gonçalves, Gisela; Pereira, Natália-De-Pinho; Toniolo, Bianca-Persici (2019). "Professional associations or activists? The case of Conferp in defending an ethical identity for public relations in Brazil”. In: Ruiz-Mora, Isabel; Gonçalves, Gisela; Somerville, Ian (coords). Organizational and strategic communication research: Global trends. Covilhã (Portugal): LabComBooks, pp. 251-272. ISBN: 9789896545529

https://bit.ly/2Amikz7

Greenwood, Royston; Suddaby, Roy; Hinings, C. R. (2002). "Theorizing change: The role of professional associations in the transformation of institutionalized fields". The Academy of Management journal, v. 45, n. 1, pp. 58-80.

https://www.jstor.org/stable/3069285

https://doi.org/10.2307/3069285

Grunig, James E. (1992). "Communication, public relations and effective organizations: an overview of the book". In: Grunig, James E. (ed.). Excellence in public relations and communication management. Hillsdale, NJ: Lawrence Erlbaum Associates, pp. 1-28. ISBN: 9780805802276

Grunig, James E. (2001). "Two way symmetrical public relations: Past, present and future". In: Heath, Robert (ed.). Handbook of public relations. Thousand Oaks, CA: Sage, pp. 11-30. ISBN: 9781412909549 https://bit.ly/3cHIM4s

Grunig, James E.; Grunig, Larissa A. (1996). "Implications of symmetry for a theory of ethics and social responsibility in public relations". International Communication Association, Chicago.

https://bit.ly/35Ydt2O 
Huang, Yi-Hui (2001). "Should a public relations code of ethics be enforced?". Journal of business ethics, v. 31, n. 3, pp. 259-270.

https://doi.org/10.1023/A:1010719118448

Hunt, Tood; Tirpok, Andrew (1993). "Universal ethics code: An idea whose time has come". Public relations review, v. 19, n. 1, pp. 1-11. https://doi.org/10.1016/0363-8111(93)90025-8

Kent, Michael L.; Taylor, Maureen (2002). "Toward a dialogic theory of public relations". Public relations review, v. 28, n. 1, pp. 21-37.

https://doi.org/10.1016/S0363-8111(02)00108-X

Ki, Eyun-Jung; Kim, Soo-Yeon (2010). "Ethics codes of public relations firms in the United States and South Korea”. Journalism \& mass communication quarterly, v. 87, n. 2, pp. 363-377.

https://doi.org/10.1177/107769901008700209

Kolic-Stanic, Matilda (2019). "Transparency in public relations: Evidence from associations' ethics codes". Interdisciplinary description of complex systems, v. 17, n. 2-B, pp. 417-429.

https://doi.org/10.7906/indecs.17.2.15

Kruckeberg, Dean (1989). "The need for an international code of ethics". Public relations review, v. 15, n. 2, pp. 6-18. https://doi.org/10.1016/S0363-8111(89)80050-5

Kruckeberg, Dean (1993). "Universal ethics code: Both possible and feasible”. Public relations review, v. 19, n. 1, pp. $21-31$. https://doi.org/10.1016/0363-8111(93)90027-A

Ledingham, John A.; Bruning, Stephen D. (1998). "Relationship management and public relations: Dimensions of an organization-public relationship". Public relations review, v. 24, n. 1, pp. 55-65.

https://doi.org/10.1016/S0363-8111(98)80020-9

Ledingham, John A.; Bruning, Stephen D. (2001). "Managing community relationships to maximize mutual benefits: Doing well by doing good". In: Heath, Robert L. (ed.). Handbook of public relations. Thousand Oaks, CA: Sage, pp. 527534. ISBN: 9781412909549

Leeper, Roy V. (1996). "Moral objectivity, Jurgen Habermas's discourse ethics, and public relations". Public relations review, v. 22, n. 2, pp. 39-62.

https://doi.org/10.1016/S0363-8111(96)90003-X

Lieber, Paul S. (2005). Public relations ethics: A cross-cultural analysis. LSU Doctoral dissertations.

https://digitalcommons./su.edu/gradschool_dissertations/1138

Lieber, Paul S. (2008). "Moral development in public relations: Measuring duty to society in strategic communication". Public relations review, v. 34, n. 3, pp. 244-251.

https://doi.org/10.1016/j.pubrev.2008.03.028

Lloyd, Herbert M. (1973). First report on standards and of public relations practice. IPRA Gold Paper, n. 1.

Pearson, Ron (1989). A theory of public relations ethics. Doctoral thesis. Athens, United States: Ohio University.

Pratt, Cornelius B. (1994). "Research progress in public relations ethics: An overview". Public relations review, v. 20, n. 3, pp. 217-224.

https://doi.org/10.1016/0363-8111(94)90036-1

Roth, Nancy L.; Hunt, Todd; Stavropoulos, Maria; Babik, Karen (1996). “Can't we all just get along: Cultural variables in codes of ethics". Public relations review, v. 22, n. 2, pp. 151-161. https://doi.org/10.1016/S0363-8111(96)90004-1

Seib, Phillip M.; Fitzpatrick, Kathy (2006). Public relations ethics. Mason, OH: Thomson Wadsworth. ISBN: 9780 534615987

Shin, Ho-Chang; Cha, Heewon (2000). "The need of the codes of ethics for the professionalism of public relations in Korea". Korean journal of public relations research, v. 4, n. 2, pp. 232-258.

Sriramesh, Krishnamurthy; Verčič, Dejan (2009). The global public relations handbook: Theory, research and practice ( $2^{\text {nd }}$ ed.). Florence, KY: Routledge. ISBN: 9781138043145

Taylor, Maureen; Yang, Aimei (2014). "Have global ethical values emerged in the public relations industry? Evidence from national and international professional public relations associations". Journal of business ethics, v. 130, n. 3, pp. 543-555. https://doi.org/10.1007/s10551-014-2226-4

Traverse-Healy, Tim (1998). Public relations and propaganda. Values compared. IPRA Gold Paper, n. 6. 
Watson, Tom (2014). "IPRA Code of Athens. The first international code of public relations ethics: Its development and implementation since 1965". Public relations review, v. 40, n. 4, pp. 707-714.

https://doi.org/10.1016/j.pubrev.2013.11.018

Wood, Greg (2000). "A cross cultural comparison of the contents of codes of ethics: USA, Canada and Australia". Journal of business ethics, v. 25, n. 4, pp. 287-298.

https://doi.org/10.1023/A:1006034209956

Wright, Donald K. (1993). "Enforcement dilemma: Voluntary nature of public relations codes". Public relations review, v. 19, n. 1, pp. 13-20.

https://doi.org/10.1016/0363-8111(93)90026-9

Zerfass, Ansgar; Verčič, Dejan; Verhoeven, Piet; Moreno, Ángeles; Tench, Ralph; (2019). European communication monitor 2019. Exploring trust in the profession, transparency, artificial intelligence and new content strategies. Results of a survey in 46 countries. Brussels: Euprera, EACD, Quadriga Media Berlin.

https://www.communicationmonitor.eu/wp-content/uploads/dlm_uploads/ECM19-European-CommunicationMonitor-2019.pdf

Zerfass, Ansgar; Wiesenberg, Markus; Tench, Ralph; Romenti, Stefania (2019). Trust in communicators. How the general population trusts journalists, public relations professionals, marketeers and other communicators: A comparative study in Germany, Italy and the United Kingdom. Brussels: Euprera.

http://euprera.org/2019/10/23/trust-in-communicators-study-results-launched-today

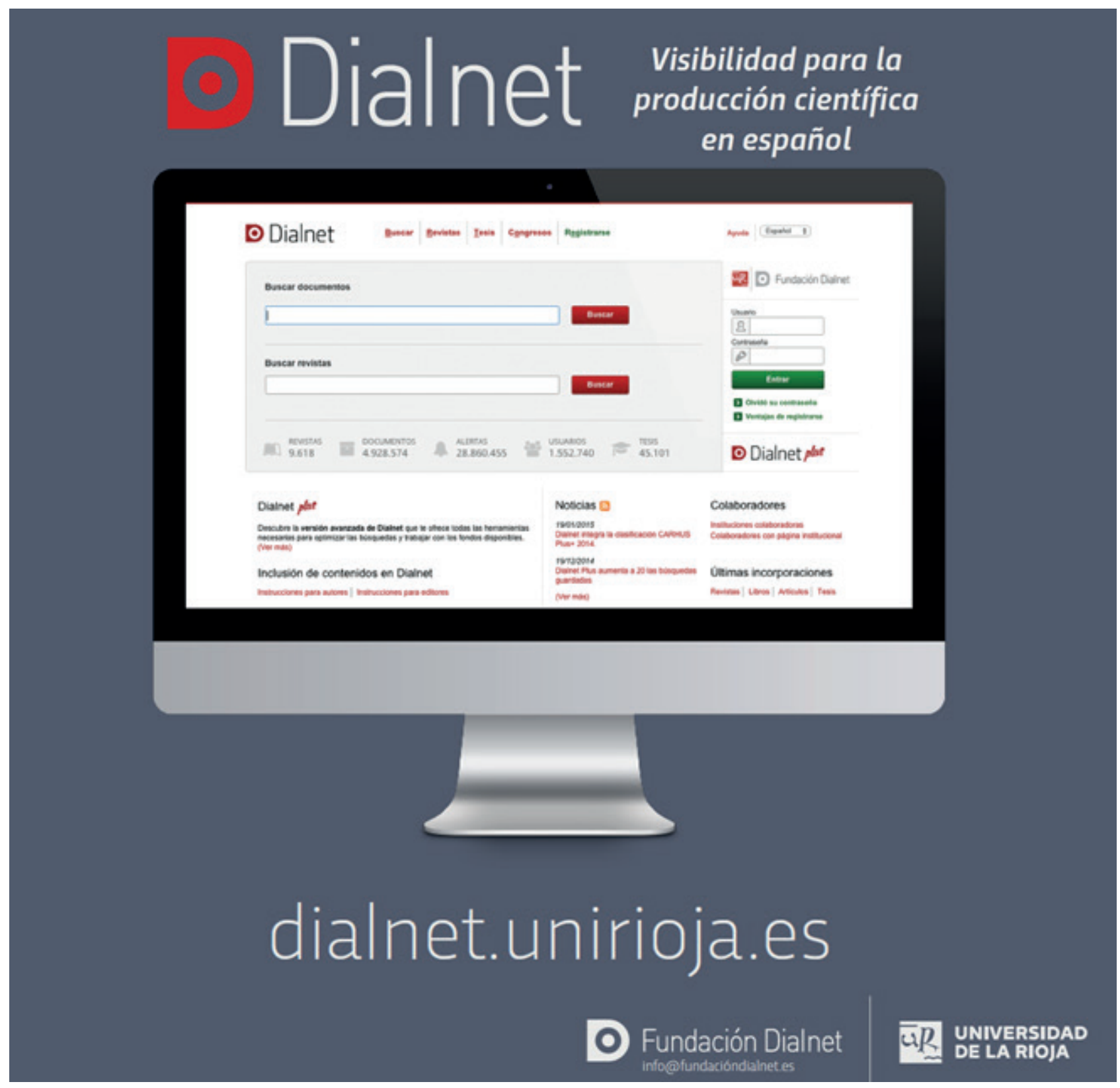

